\title{
Article \\ Optimal Water Backwashing Condition in Combined Water Treatment of Alumina Microfiltration and PP Beads
}

\author{
Hyungmin Cho, Gihoon Yoon, Minjae Kim and Jin Yong Park * (D) \\ Department of Environmental Sciences \& Biotechnology, Hallym University, Chunchon 24252, Korea; \\ tlr0987@naver.com (H.C.); dbsrlgns416@naver.com (G.Y.); vhalrj@naver.com (M.K.) \\ * Correspondence: jypark@hallym.ac.kr
}

Citation: Cho, H.; Yoon, G.; Kim, M.; Park, J.Y. Optimal Water Backwashing Condition in Combined Water Treatment of Alumina

Microfiltration and PP Beads.

Membranes 2022, 12,92. https:// doi.org/10.3390/membranes 12010092

Academic Editor: Rahul Singh

Received: 24 December 2021

Accepted: 13 January 2022

Published: 15 January 2022

Publisher's Note: MDPI stays neutral with regard to jurisdictional claims in published maps and institutional affiliations.

Copyright: (C) 2022 by the authors. Licensee MDPI, Basel, Switzerland. This article is an open access article distributed under the terms and conditions of the Creative Commons Attribution (CC BY) license (https:// creativecommons.org/licenses/by/ $4.0 /)$.

\begin{abstract}
Membrane fouling is a dominant limit of the membrane separation process. In this research, the optimal water backwashing to solve the membrane fouling problem was investigated in the combined water treatment process of alumina MF and pure polypropylene (PP) beads. Additionally, the influence of membrane shape (tubular or seven channel) was examined, depending on the water backwashing period. The optimal backwashing time (BT) could be $20 \mathrm{~s}$ in the combined water treatment process, because of the highest total treated volume $\left(\mathrm{V}_{\mathrm{T}}\right)$ in our BT 6-30 s conditions. The optimal backwashing period (BP) could be $6 \mathrm{~min}$, because of the minimum membrane fouling and the maximum $\mathrm{V}_{\mathrm{T}}$ in the combined process of tubular alumina MF and PP beads. The resistance of reversible membrane fouling $\left(\mathrm{R}_{\mathrm{rf}}\right)$ showed a major resistance of total membrane fouling, and that of irreversible membrane fouling $\left(\mathrm{R}_{\mathrm{if}}\right)$ was a minor one, in the combined process using tubular or seven channel MF. The $R_{\text {if }}$ showed a decreasing trend obviously, as decreasing BT from NBW to 2 min for seven channel MF. It means that the more frequent water backwashing could be more effective to control the membrane fouling, especially irreversible fouling, for seven channel membranes than tubular membranes.
\end{abstract}

Keywords: microfiltration; water backwashing; photo-oxidation; polypropylene bead; combined treatment; water treatment; alumina

\section{Introduction}

In the membrane separation process, usually, membrane fouling was accomplished by the adsorption-precipitation of organic and inorganic compounds on the membrane surface or inside the membrane and leads to decreasing the permeate flux, increasing membrane cleaning costs, and reducing the membrane life. Strategies for reducing membrane fouling remain insufficient, that is, the major hindrance in the successful application of membrane separation technology, although considerable progress has been made in membrane fouling control [1,2]. Furthermore, the fouling behavior, fouling factors and fouling control strategies were reviewed in membrane bioreactors (MBRs) [1]. The modified membranes were investigated for their anti-biofouling performance in the viewpoints of the anti-adhesion and anti-bacterial effects. The anti-adhesion method which prohibits the initial attachment of bacteria on a membrane surface was more efficient than the anti-bacterial approach that focuses on killing bacteria already involved on the membrane surface [2].

Natural organic matter (NOM) is a dominant constituent of membrane fouling in lowpressure membrane filtration. Numerous protective procedures to restrict NOM fouling have been established and comprehensively verified, such as coagulation, oxidation, ion exchange, carbon adsorption, and mineral oxide adsorption [3]. A new adsorbent, such as heated aluminum oxide powder, was employed in an absolutely automated pilot water treatment process to exclude NOM in the surface water [4].

To control membrane fouling, backpulsing/backwashing can be applied periodically to remove reversible fouling $[5,6]$. When the performance of the membrane decreases 
by $50-60 \%$, chemical cleaning is needed to remove irreversible fouling and to restore the membrane performance [7]. In this research, periodic water backwashing was performed to inhibit the membrane fouling. In recent times, the combined process of membrane separation and photo-oxidation by ultraviolet (UV) irradiation can effectively solve the membrane fouling problem, mentioned above [8]. Moreover, the influence of UV irradiation on nanofiltration (NF) membrane biofouling had been researched in a pilot scale, and the two pilots were fed either granular activated carbon (GAC)-filtered water or UV-irradiated GAC-filtered water. UV pre-treatment did not give an impact on the organic carbon concentration; however, it was related to a much lower longitudinal pressure drop (LPD) increase, and moderate permeate flux decrease [9].

The combined technology not only retains the benefits of each technology but also yields synergistic properties to solve the limits of only a method. Furthermore, the contaminants like NOM can be oxidized by UV irradiation, and organic matters are reduced partially by controlling the residence time in the reacting process. In other words, the membrane separation has a limitation as a selective barrier that only molecules smaller than its pore size can be separated. In conclusion, the combined process could increase the photo-oxidation effectiveness and acquire outstanding effluent quality. Moreover, the influence of UV irradiation on the nano-hybrid PES-NanoZnO membrane in terms of flux and rejection efficiency has been discussed [10]. Additionally, an evaluation of the treatment effectiveness of surface water in a combined process of numerous advanced oxidation processes and ultrafiltration (UF) was published [11]. In this research, a combined process of alumina ceramic membrane and pure PP beads with UV irradiation was applied to advanced water treatment for the purpose of high water quality.

Ceramic membranes employed in this research usually have three times higher costs than polymeric membranes with similar membrane surfaces; however, those have various advantages, which are mechanical, thermal and chemical resistance, and a long lifetime. Those were economical, compared with polymeric membranes, because of higher permeate flux and practically permanent lifetime [12]. Currently, the modified and improved ceramic membranes have been applied extensively in water or wastewater treatment in the world. The various methods applied for ceramic membrane modification, focusing on utilization in oily wastewater were compared [13]. Ceramic membrane application in the treatment of emulsion wastewater was the development trend, and their useful guidance and reference were provided [14]. The impact of the characteristics of soluble algal organic matter (AOM) on the membrane fouling was examined for seven-channel tubular ceramic microfiltration (MF) membranes at a lab scale [15]. The effect of the interaction between aquatic humic substances and the AOM resulting from Microcystis aeruginosa was investigated on the membrane fouling of a ceramic MF [16].

Photo-oxidation has a lot of advantages, which are high effectiveness, low energy consumption and a wide range of applications. The mechanism of the photo-oxidation process is to mineralize organic compounds to small inorganic molecules by the oxidization of most of them, specifically non-biodegradable organic pollutants. Furthermore, it is one of the excellent processes of advanced water treatment. For these motivations, the photo-oxidation process, that was employed in this research, has been applied widely [17-21]. Electrooxidation of aniline applying boron-doped diamond (BDD) electrodes was more effective than $\mathrm{UV} / \mathrm{H}_{2} \mathrm{O}_{2}$ because it has an $87 \%$ lower operational cost [17]. The photo-oxidation that happened in the water column could be utilized to progress the destruction of residual organic matter in the solution by sustaining the plasma after processing a given amount of organic liquids [19]. Atomic Force Microscopy images showed smoother surfaces after UV photo-oxidation; however, atom treatment resulted in trivial changes in surface roughness. Rinsing the treated surfaces with ethanol solvent partially decreased it, representing the formation of a weak boundary during treatment [20]. The photo-oxidation of clopyralid included either hydroxylation or dechlorination of the ring; however, metaldehyde underwent hydroxylation and produced acetic acid as a major end product [21]. In addition, degradation of humic acid (HA), which was contained in a synthetic solution used in this 
research, via photoelectrocatalysis (PEC) process and corresponding disinfection byproduct formation potential (DBPFP) were investigated, and the PEC process was found to be effective in reducing dissolved organic carbon concentration [22].

In our research group, the results for the effect of water backwashing and PP beads in the combined water treatment process of various ceramic membranes and titanium dioxide $\left(\mathrm{TiO}_{2}\right)$ photocatalyst-coated polypropylene (PP) were published in Desal. Water Treat. $[23,24]$. On the other hand, roles of adsorption and photo-oxidation in the combined water treatment process of tubular carbon fiber UF and pure PP beads with UV irradiation and water backwashing was reported by our group in Desal. Water Treat. [25]. The final dimensionless permeate flux $\left(\mathrm{J}_{180} / \mathrm{J}_{0}\right)$ after $180 \mathrm{~min}$ 's operation increased as PP beads increased in the combined water treatment of carbon fiber UF membrane and PP beads [26]. Therefore, the PP beads could increase the membrane lifetime in this combined water process.

In this research, the optimal water backwashing was investigated on membrane fouling and treatment efficiency of dissolved organic matter (DOM) and turbidity in the combined water treatment process of seven channels or tubular alumina MF membranes and pure polypropylene (PP) beads with UV irradiation. Substituting DOM and turbidity, a constant quantity of humic acid (HA) and kaolin was dissolved in distilled water. This study was the unique application of pure PP beads and UV irradiation to investigate the influence of water backwashing period (BP) and time (BT) in the combined water treatment process of MF membrane. A combined module was composed of the MF membrane and the PP beads, those were fluidized between the gap of the alumina membrane and the acryl module case. The results of the combined process of the seven channels alumina MF (pore size: $0.4 \mu \mathrm{m}$ ) membrane and pure PP beads with water backwashing were compared with those of tubular alumina MF (pore size: $0.1 \mu \mathrm{m}$ ) membrane, to examine the effects of membrane shape and pore size on membrane fouling and treatment efficiency. The results were compared with our previous studies [24,25], which used tubular carbon fiber UF and $\mathrm{TiO}_{2}$ photocatalyst-coated PP [24], or pure PP beads [25] in the combined water treatment process.

\section{Materials and Methods}

\subsection{Membranes and Polypropylene (PP) Beads}

The tubular alumina (NCMT-7231, pore size $0.1 \mu \mathrm{m}$ ) and seven channels alumina MF (HC04, pore size $0.4 \mu \mathrm{m}$ ) membranes, were manufactured in Nanopore Inc. (Seoul, Korea) and Dongseo Industry (Chungnam, Korea), respectively, were applied in this research. The specification of the tubular and seven channels alumina membranes was compared in Table 1. Cross-sectional area of the pore, flow velocity and Reynolds number (Re) in membrane channel were given for flow pattern. Turbulent flow $(\operatorname{Re}>4000)$ was happened in NCMT-7231; however, laminar flow $(\operatorname{Re}<2100)$ in HC10.

The pure polypropylene (PP) beads of 4-6 mm, which was purchased from SKC (Seoul, Korea), were employed in this research, those of the average weight was $39.9 \mathrm{mg}$. Substituting natural organic matters and fine inorganic particles in natural water sources, a constant quantity of HA and kaolin was dissolved in distilled water. In this experimental study, it was utilized as synthetic feed water. For photo-oxidation of DOM, two UV lamps (F8T5BLB, Sankyo, Tokyo, Japan) irradiated UV with $352 \mathrm{~nm}$ from the acryl module outside. 
Table 1. Specification of tubular and seven channel alumina ceramic MF membranes employed in this experimental research.

\begin{tabular}{ccc}
\hline Membrane Model & NCMT-7231 & HC10 \\
\hline Pore size $(\mu \mathrm{m})$ & 0.4 & 0.1 \\
No. of channels & 1 & 7 \\
Outer diameter $(\mathrm{mm})$ & 8 & 20 \\
Inner diameter $(\mathrm{mm})$ & 6 & 4 \\
Length $(\mathrm{mm})$ & 254 & 245 \\
Surface area $\left(\mathrm{cm}^{2}\right)$ & 47.9 & 215 \\
Cross sectional area of & 0.283 & 0.880 \\
pore $\left(\mathrm{cm}^{2}\right)$ & 58.9 & 18.9 \\
Flow velocity in & 3510 & 751 \\
channel $(\mathrm{cm} / \mathrm{s})$ & $\alpha$-alumina & $\alpha$-alumina \\
Reynolds number in channel & Nanopore Inc. (Korea) & Dongseo Industry (Korea) \\
Material & &
\end{tabular}

\subsection{Experimental Procedures}

To eliminate the turbidity and DOM, the pure PP beads were fluidized in the space between the acryl module inside and the alumina membrane outside. Furthermore, a 100 mesh $(0.150 \mathrm{~mm})$ sieve, that was much smaller than $4-6 \mathrm{~mm}$ of the PP beads size employed here, was mounted at the outlet of the combined module, because of the PP beads loss out of the module.

The combined water treatment process (6) of alumina MF membrane and the pure PP beads (7), which were used in the previous study [23], as displayed in Figure 1. A periodic water backwashing utilizing permeated water from the combined module was accomplished for the MF membrane. The combined module (6) was provided with the PP beads fluidizing between the gap of the MF membrane and the acryl module case.

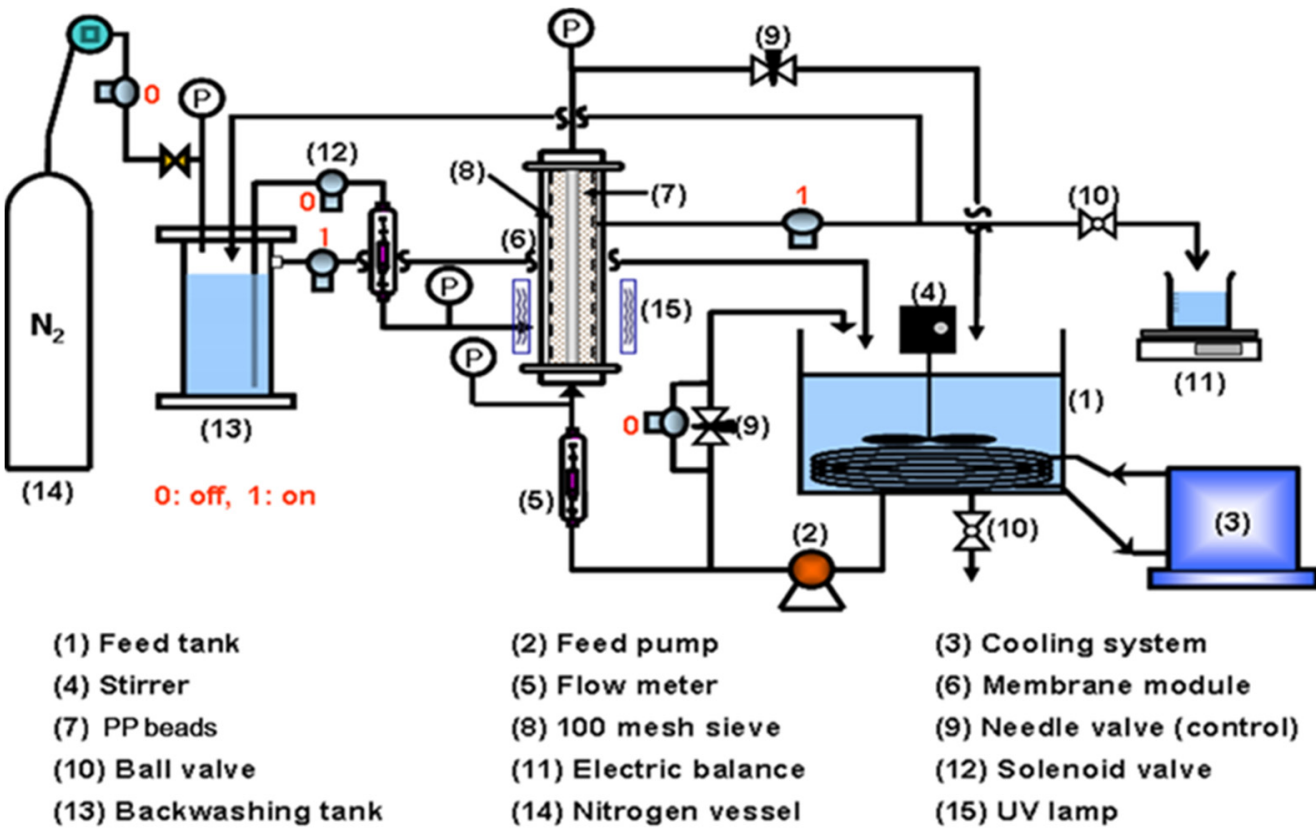

Figure 1. Apparatus of combined water treatment process of tubular or seven channel MF membrane and PP beads with periodic water backwashing.

The three pressure gages $(\mathrm{P})$ were installed at the membrane inlet, membrane outlet, and backwashing water inlet, to measure transmembrane pressure (TMP) and backwashing water pressure. Then, $10 \mathrm{~L}$ of the water, which was composed of HA and kaolin, 
was contained in the feed tank (1). To preserve a constant viscosity of water, the feedwater temperature was constantly maintained by a temperature control water circulator (3) (Model 1146, VWR, Atlanta, GA, USA). To maintain the homogeneous feed water, it was continuously mixed by a stirrer (4), and it flowed into the MF membrane inside by a pump (2) (Procon, Standex Co., Smyna, TN, USA). A flowmeter (5) (NP-127, Tokyo Keiso, Japan) measured the feed flow rate to the membrane module. Regulating valves (9) of both the bypass pipe of the pump (2) and the concentrate pipe could maintain constant flow rate and pressure of the feed water that flowed into the combined module. An electric balance (11) (Ohaus, Newark, NJ, USA) measured the permeate flux treated by both the MF membrane and the PP beads. During the permeate flux had not been measured, the permeate water flowed into the backwashing tank (13). To maintain a constant concentration of the feed water during operation, the treated water was recycled to the feed tank (1) after it was over a certain level in the water backwashing tank (13). Physical washing was accomplished by a brush inside the membrane channels after each of the three hours' procedures. After that, the permeate flux was measured to evaluate the resistances of irreversible and reversible membrane fouling. The real pictures for the combined water treatment process and seven channel MF membranes were displayed in Figure 2.

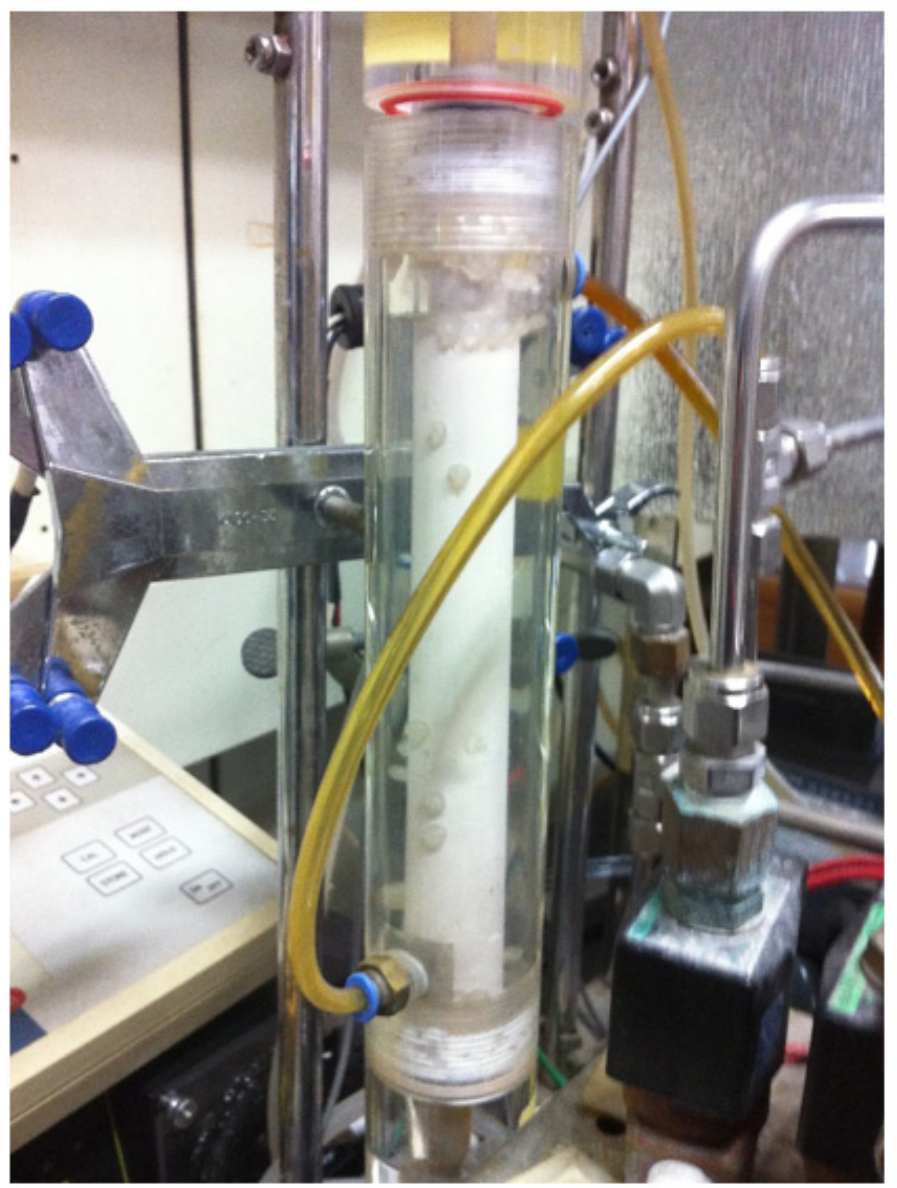

(a)

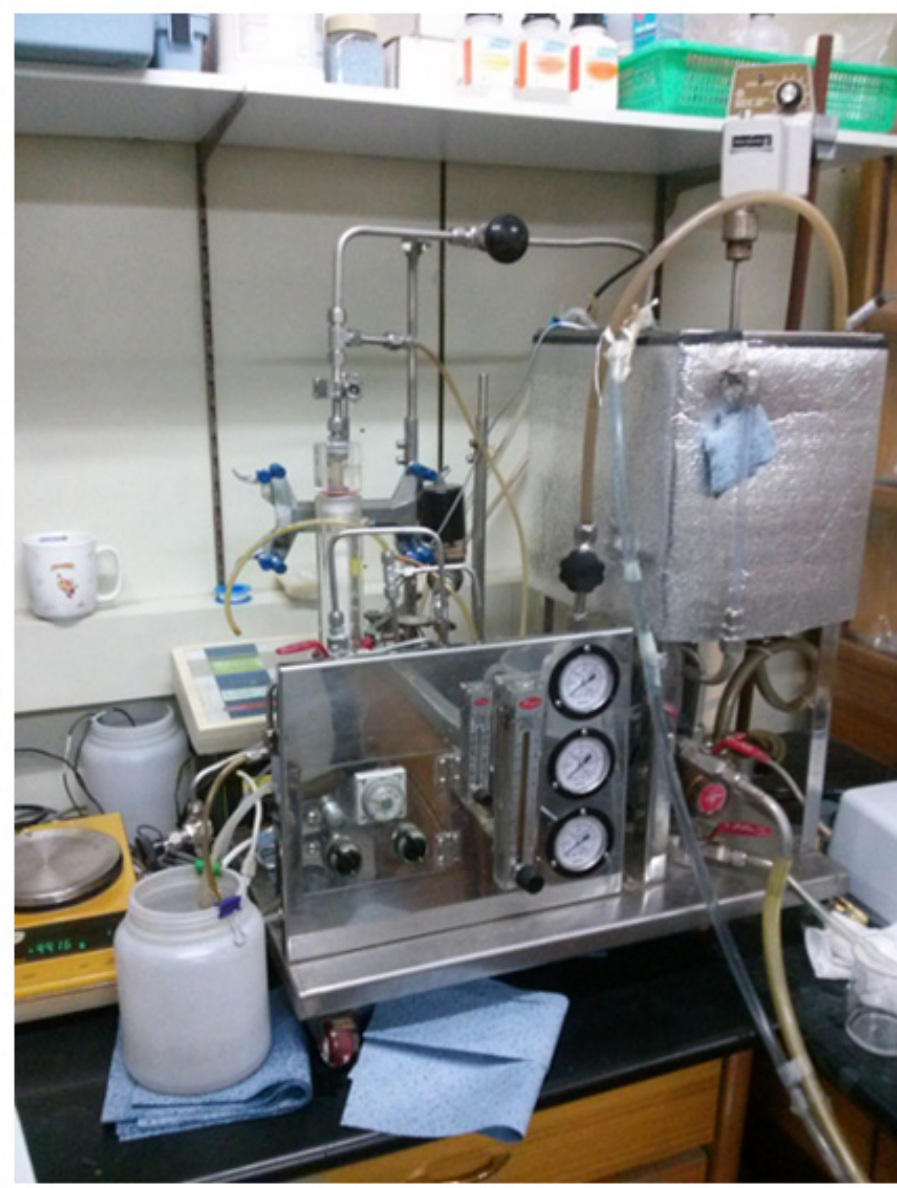

(b)

Figure 2. Combined water treatment process of tubular or seven channel MF membrane and PP beads with periodic water backwashing: (a) seven channel MF membrane; (b) total combined system.

To investigate the influence of the water backwashing period (BP), BP was changed from 2 to $10 \mathrm{~min}$, and no backwashing (NBW), in the condition that fixed backwashing time (BT) at $10 \mathrm{~s}$. Furthermore, to examine the BT influence, BT was changed from 30 to $6 \mathrm{~s}$, and NBW, at stationary BP $10 \mathrm{~min}$. HA and kaolin were set at $10 \mathrm{mg} / \mathrm{L}$ and $30 \mathrm{mg} / \mathrm{L}$ in all 
of the experimental research, respectively. During the total $180 \mathrm{~min}$ 's operation time, the permeate flux (J) was checked at each experimental condition. In the combined process of tubular NCMT-7231 MF, TMP was sustained constant at 1.8 bar, and the water backwashing pressure at 2.5 bar; however, in the case of seven channel HC04 MF, TMP was fixed at $0.8 \mathrm{bar}$, and the water backwashing pressure at 1.0 bar, because the HC04 had 4.49 times higher membrane surface than NCMT-7231. The feed flow rate was fixed at $1.0 \mathrm{~L} / \mathrm{min}$, and the feedwater temperature was at $20^{\circ} \mathrm{C}$ in all experiments. The PP beads concentration was set at $40 \mathrm{~g} / \mathrm{L}$ in the combined module.

\subsection{Analytical Methods}

The quality of feed and treated water was analyzed every 30 min during each experiment, for evaluating the treatment efficiencies of turbidity and DOM. Turbidity was checked by a turbidimeter $\left(2100 \mathrm{~N}\right.$, Hach, Ames, IA, USA). Before checking $\mathrm{UV}_{254}$ absorbance, each sample was filtered by a $0.2 \mu \mathrm{m}$ syringe filter to eliminate turbidity. The $\mathrm{UV}_{254}$ absorbance was examined by a UV spectrophotometer (Genesys 10 UV, Thermo, Pittsburgh, PA, USA) to measure DOM. The detection limits of the turbidimeter and UV spectrophotometer were $0 \sim 4000 \mathrm{NTU}( \pm 0.001 \mathrm{NTU})$ and $-0.1 \sim 3.0 \mathrm{~cm}^{-1}\left( \pm 0.001 \mathrm{~cm}^{-1}\right)$, respectively.

\subsection{Membrane Recovery Methods}

After finishing each experiment, all of the synthetic solution was discharged from the combined water treatment system, and distilled water was circulated in the line of the system for $15 \mathrm{~min}$. The PP beads were collected, and the ceramic membranes were separated from the module. Most of the fouling materials inside the alumina membrane could be removed by combusting at $550{ }^{\circ} \mathrm{C}$ in a furnace over $30 \mathrm{~min}$. After cooling the membrane, it was immersed in a nitric acid $\left(\mathrm{HNO}_{3}\right)$ of $15 \%$ for $24 \mathrm{~h}$, and in a sodium hydroxide $(\mathrm{NaOH})$ solution of $0.25 \mathrm{~N}$ for $3 \mathrm{~h}$, to dissolve out organic or inorganic contaminants that remained inside the membrane. For rinsing and rejecting air in the membrane pore, it was kept in distilled water for $24 \mathrm{~h}$.

Before operating a new experiment, the water permeated flux $\left(\mathrm{J}_{\mathrm{W}}\right)$ was measured for evaluating the membrane recovery when a normal operation was performed with distilled water. If the error of $J_{W}$ were less than $5 \%$, the recovered membrane was installed inside the module for another experiment. The recovered membrane was applied in all of the experiments to minimize the impact of membrane condition on the treatment efficiency.

\subsection{Resistance-in-Series Filtration Model}

Applying the resistance-in-series filtration Equation (1) as the same method as the previous study [23], where $\triangle \mathrm{P}$ is TMP, resistances of the membrane, boundary layer, and membrane fouling $\left(R_{m}, R_{b}, R_{f}\right)$ were evaluated from permeate flux $(J)$ data.

$$
\mathrm{J}=\Delta \mathrm{P} /\left(\mathrm{R}_{\mathrm{m}}+\mathrm{R}_{\mathrm{b}}+\mathrm{R}_{\mathrm{f}}\right)
$$

In detail, the equation was simplified to Equation (2) for a new membrane, because there were no resistances of the boundary layer and membrane fouling. Finally, the $R_{m}$ could be extracted from $J$ data for a new membrane.

$$
\mathrm{J}=\Delta \mathrm{P} / \mathrm{R}_{\mathrm{m}}
$$

For the solution prepared with HA and kaolin, the equation was revised to Equation (3) at the initial time, and $R_{b}$ could be calculated using initial $J\left(J_{0}\right)$ and $R_{m}$ values.

$$
\mathrm{J}=\Delta \mathrm{P} /\left(\mathrm{R}_{\mathrm{m}}+\mathrm{R}_{\mathrm{b}}\right)
$$

In addition, resistances of the irreversible and reversible membrane fouling $\left(R_{i f}, R_{r f}\right)$ could be determined from J values, before and after physical washing utilizing a brush inside the membrane. 


\section{Results and Discussions}

The optimal water backwashing was investigated in the combined water treatment process of tubular (NCMT-7231) or seven channels (HC10) alumina MF membrane and pure PP beads with periodic water backwashing and UV irradiation.

\subsection{Influence of Water Backwashing Time (BT) on Membrane Fouling and Treatment Efficiency}

The influence of water backwashing time was investigated for the solution of HA $10 \mathrm{mg} / \mathrm{L}$, kaolin $30 \mathrm{mg} / \mathrm{L}$. The resistances of membrane fouling $\left(\mathrm{R}_{\mathrm{f}}\right)$ maintained the highest values at NBW from 30 min's operation, and the lowest at BT $20 \mathrm{~s}$ with BP 10 min until $120 \mathrm{~min}$; however, the minimum at BT $30 \mathrm{~s}$ after $120 \mathrm{~min}$, as compared in Figure 3a. It proved that the BT $20 \mathrm{~s}$ could be sufficient to inhibit the membrane fouling until $120 \mathrm{~min}$ 's operation; however, longer BT $30 \mathrm{~s}$ was more effective than BT $20 \mathrm{~s}$ after $120 \mathrm{~min}$ in this combined water treatment process of tubular alumina MF and PP beads.

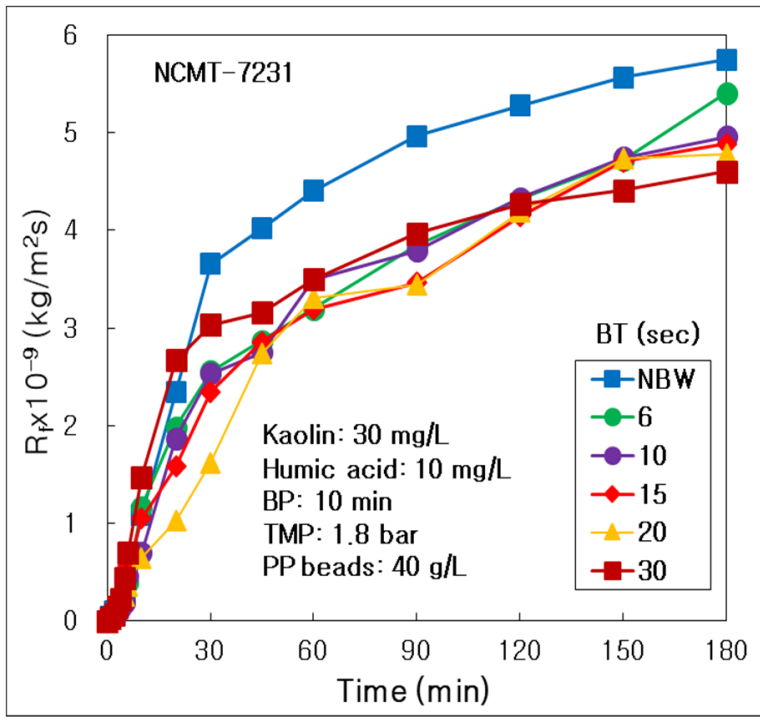

(a)

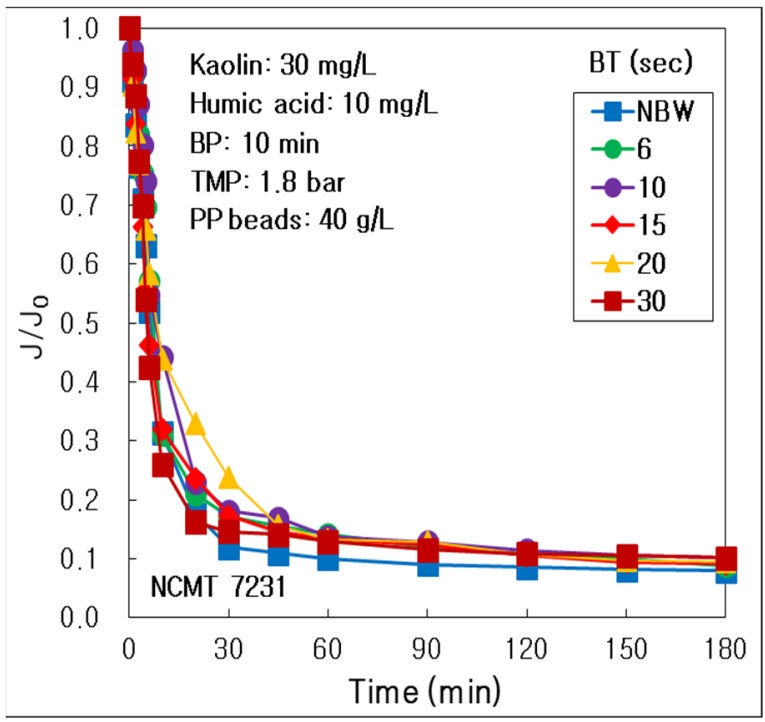

(b)

Figure 3. Influence of water backwashing time (BT) in the combined process of tubular alumina MF (NCMT-7231) and PP beads with UV irradiation and periodic water backwashing: (a) Resistance of membrane fouling; (b) Dimensionless permeate flux.

In our previous work [24], for the combined water treatment process of tubular carbon fiber ultrafiltration (UF) and photocatalyst-coated PP beads, the $\mathrm{R}_{\mathrm{f}}$ maintained the lowest values at BT $30 \mathrm{~s}$ and the highest at NBW condition during all of 180 min's operation. The previous result did not exactly agree with the trend of BT influence in this research using tubular alumina MF, because the UF membrane had a smaller pore size $0.05 \mu \mathrm{m}$ than $0.1 \mu \mathrm{m}$ of the alumina MF. It proved that the water backwashing time should be adjusted depending on membrane pore size in the combined water treatment process.

As presented in Figure $3 b$, the dimensionless permeate flux $\left(\mathrm{J} / \mathrm{J}_{0}\right)$, where $\mathrm{J}_{0}$ was the initial permeate flux predicted using the initial two data by an extrapolation method, as compared to investigate a BT influence on the relative decline of permeate flux. The $\mathrm{J} / \mathrm{J}_{0}$ values overlapped almost at every BT condition; however, those at BT $20 \mathrm{~s}$ showed the highest from 10 to 30 min's operation. In the previous work [24], for the combined process of tubular carbon fiber UF and photocatalyst-coated PP beads, the $\mathrm{J} / \mathrm{J}_{0}$ tended to increase significantly as increasing BT from NBF to $30 \mathrm{~s}$, because the longer water backwashing should more efficiently inhibit the cake accumulation on the membrane surface and the fouling inside the membrane.

As arranged in Table 2, the final J after 180 min's operation $\left(\mathrm{J}_{180}\right)$ increased dramatically from NBW to BT $30 \mathrm{~s}$, because the final $R_{f}\left(R_{f, 180}\right)$ decreased obviously as increasing BT. 
It proved that the permeate flux could maintain the highest values at the longest BT $30 \mathrm{~s}$ because the membrane fouling was inhibited effectively at BT $30 \mathrm{~s}$ in the combined water treatment process. In conclusion, the $\mathrm{J}_{180} / \mathrm{J}_{0}$ after 180 min's operation at BT $30 \mathrm{~s}$ showed the highest 0.101 , which was 1.28 times higher than 0.079 at NBW condition. However, the total treated water volume $\left(\mathrm{V}_{\mathrm{T}}\right)$ had the highest $3.13 \mathrm{~L}$ at BT $20 \mathrm{~s}$, because J maintained higher from 10 to 30 min's operation than those of other BT conditions, as shown in Figure 3b. Finally, the optimal BT condition could be $20 \mathrm{~s}$ in the combined water treatment process, because of the maximum $\mathrm{V}_{\mathrm{T}}$ in our experimental BT conditions. In the previous work [24], for the combined process of tubular carbon fiber UF and photocatalyst-coated PP beads, the highest $\mathrm{V}_{\mathrm{T}} 3.00 \mathrm{~L}$ could be acquired at BT $30 \mathrm{~s}$, which was 1.33 times higher than the lowest 2.25 L at NBW. The optimal BT for the former result [24] could be $30 \mathrm{~s}$ otherwise, because of different pore sizes.

Table 2. Influence of water backwashing time on filtration factors in the combined process of tubular alumina MF (NCMT-7231) membrane and PP beads with periodic water backwashing.

\begin{tabular}{ccccccc}
\hline BT (s) & NBW * & $\mathbf{6}$ & $\mathbf{1 0}$ & $\mathbf{1 5}$ & $\mathbf{2 0}$ & $\mathbf{3 0}$ \\
\hline $\mathrm{R}_{\mathrm{m}} \times 10^{-9}\left(\mathrm{~kg} / \mathrm{m}^{2} \mathrm{~s}\right)$ & 0.484 & 0.490 & 0.489 & 0.484 & 0.493 & 0.495 \\
$\mathrm{R}_{\mathrm{b}} \times 10^{-9}\left(\mathrm{~kg} / \mathrm{m}^{2} \mathrm{~s}\right)$ & 0.011 & 0.037 & 0.070 & 0.007 & 0.013 & 0.023 \\
$\mathrm{R}_{\mathrm{f}, 180 \times 10^{-9}\left(\mathrm{~kg} / \mathrm{m}^{2} \mathrm{~s}\right)}$ & 5.742 & 5.404 & 4.958 & 4.885 & 4.781 & 4.597 \\
$\mathrm{R}_{\mathrm{if}} \times 10^{-9}\left(\mathrm{~kg} / \mathrm{m}^{2} \mathrm{~s}\right)$ & 0.247 & 0.214 & 0.086 & 0.147 & 0.117 & 0.136 \\
$\mathrm{R}_{\mathrm{rf}} \times 10^{-9}\left(\mathrm{~kg} / \mathrm{m}^{2} \mathrm{~s}\right)$ & 5.495 & 5.190 & 4.873 & 4.739 & 4.663 & 4.461 \\
$\mathrm{~J}_{0}\left(\mathrm{~L} / \mathrm{m}^{2} \mathrm{hr}\right)$ & 1282 & 1207 & 1137 & 1294 & 1255 & 1225 \\
$\mathrm{~J}_{180}\left(\mathrm{~L} / \mathrm{m}^{2} \mathrm{hr}\right)$ & 102 & 107 & 115 & 118 & 120 & 124 \\
$\mathrm{~J}_{180} / \mathrm{J}_{0}$ & 0.079 & 0.089 & 0.101 & 0.091 & 0.096 & 0.101 \\
$\mathrm{~V}_{\mathrm{T}}(\mathrm{L})$ & 2.43 & 2.76 & 2.80 & 2.88 & 3.13 & 2.60 \\
\hline
\end{tabular}

* no backwashing.

As compared in Table 2 , the resistance of the boundary layer $\left(R_{b}\right)$, which was formed by concentration polarization on the membrane surface, was the lowest at BT $15 \mathrm{~s}$ in the combined process of tubular alumina MF and PP beads. It proved that the BT $15 \mathrm{~s}$ could reduce the concentration polarization on the membrane surface the most effectively. The $R_{f, 180}$ after 180 min's operation at NBW condition showed the maximum $5.742 \times 10^{9} \mathrm{~kg} / \mathrm{m}^{2} \mathrm{~s}$, which was 1.25 times higher than the minimum $4.597 \times 10^{9} \mathrm{~kg} / \mathrm{m}^{2} \mathrm{~s}$ at BT $30 \mathrm{~s}$ with BP $10 \mathrm{~min}$.

Resistances of membrane, boundary layer, final, irreversible and reversible membrane fouling $\left(R_{m}, R_{b}, R_{f, 180}, R_{i f}, R_{r f}\right)$ were obviously compared as bar graphs in Figure 4. Because the $R_{r f}$ had a lot of portions of $R_{f, 180}$, it could be a major membrane fouling in this combined water treatment process. It proved that most of the membrane fouling could be easily removed by physical cleaning. In addition, the $\mathrm{R}_{\mathrm{rf}}$ decreased clearly from NBW to BT $30 \mathrm{~s}$; however, the $\mathrm{R}_{\mathrm{if}}$ did not show a constant trend depending on BT condition and was the lowest value at BT $10 \mathrm{~s}$. It means that the BT $10 \mathrm{~s}$ could reduce the irreversible membrane fouling efficiently in our BT range.

As arranged in Table 3, the treatment efficiencies of turbidity showed almost constant values in the range of $99.5 \%$ and $99.7 \%$, independent of the BT condition. It proved that the turbid matters could be removed effectively over $99.5 \%$ by microfiltration and PP beads adsorption in this combined water treatment process of tubular alumina MF and PP beads. In the previous work [24], for the combined process of tubular carbon fiber UF and photocatalyst-coated PP beads, the treatment efficiency of turbidity was maintained almost the same as $99.2-99.5 \%$, independent of water BT. It agreed exactly with the result utilizing tubular alumina MF and pure PP beads. 


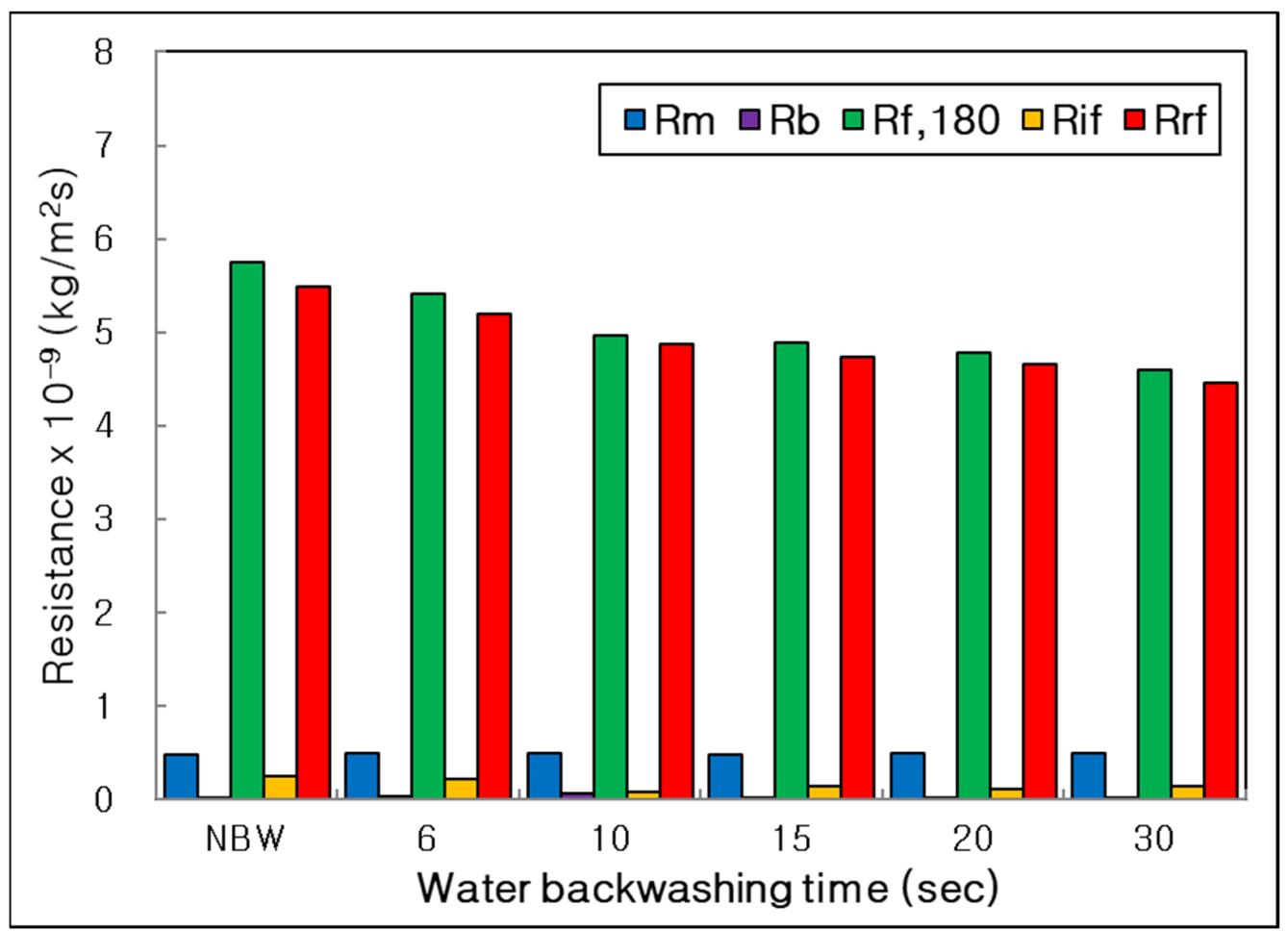

Figure 4. Influence of water backwashing time on resistances of membrane, boundary layer, final, irreversible and reversible membrane fouling $\left(R_{m}, R_{b}, R_{f, 180}, R_{i f}, R_{r f}\right)$ in the combined process of tubular alumina MF (NCMT-7231) and PP beads with UV irradiation and periodic water backwashing.

Table 3. Water quality and treatment efficiency of turbidity in the combined process of tubular alumina MF (NCMT-7231) and PP beads for the influence of water backwashing time.

\begin{tabular}{|c|c|c|c|c|c|}
\hline \multirow{3}{*}{$\begin{array}{l}\text { BT } \\
\text { (s) }\end{array}$} & \multicolumn{4}{|c|}{ Turbidity (NTU) } & \multirow{3}{*}{$\begin{array}{c}\text { Average } \\
\text { Treatmen } \\
\text { Efficiency } \\
\quad(\%)\end{array}$} \\
\hline & \multicolumn{2}{|c|}{ Feed Water } & \multicolumn{2}{|c|}{ Treated Water } & \\
\hline & Range & Average & Range & Average & \\
\hline $\mathrm{NBW} *$ & $156.0 \sim 157.0$ & 156.8 & $0.447 \sim 0.512$ & 0.488 & 99.7 \\
\hline 6 & $153.0 \sim 155.0$ & 154.2 & $0.668 \sim 0.722$ & 0.694 & 99.6 \\
\hline 10 & $153.0 \sim 155.0$ & 154.0 & $0.672 \sim 0.725$ & 0.694 & 99.5 \\
\hline 15 & $143.0 \sim 145.0$ & 144.5 & $0.607 \sim 0.620$ & 0.613 & 99.6 \\
\hline 20 & $147.0 \sim 149.0$ & 148.0 & $0.611 \sim 0.657$ & 0.635 & 99.6 \\
\hline 30 & $162.0 \sim 163.0$ & 162.5 & $0.612 \sim 0.684$ & 0.635 & 99.6 \\
\hline
\end{tabular}

* no backwashing.

The turbidity of real lake water located in Chuncheon, Korea, was the range of 33.3-39.2 NTU (average 36.3 NTU), as published by our group [27]. That of kaolin $30 \mathrm{mg} / \mathrm{L}$ solution in Table 3 was 144.5-162.5 NTU (average 153.5 NTU), which was 4.22 times higher than that of real lake water. Therefore, the kaolin solution used in this study could modify the severe quality of lake water.

As compared in Table 4, the treatment efficiency of $\mathrm{UV}_{254}$ absorbance, which could substitute the concentration of DOM (dissolved organic matters), did not present a constant trend, depending on BT; however, it showed the highest $92.4 \%$ at BT $20 \mathrm{~s}$. It proved that the optimal BT condition could be $20 \mathrm{~s}$ for DOM treatment in this combined process of tubular alumina MF and PP beads. In the previous work [25], for the combined process of carbon fiber UF and photocatalyst-coated PP beads, the treatment efficiency of DOM showed the highest $67.3 \%$ at BT $30 \mathrm{~s}$ and increased dramatically as increasing BT from NBF to $30 \mathrm{~s}$. It proved that the photocatalyst-coated PP beads were cleaned effectively by water backwashing as increasing BT from NBF to $30 \mathrm{~s}$, and finally, the DOM could be photo-oxidized or 
adsorbed effectively by the PP beads and UV irradiation. The treatment efficiency of DOM was much lower than that using tubular alumina MF and pure PP beads in this research. It seems that both the membrane and beads could affect the DOM treatment.

Table 4. Water quality and treatment efficiency of DOM ( $\mathrm{UV}_{254}$ absorbance) in the combined process of tubular alumina MF (NCMT-7231) and PP beads for the influence of water backwashing time.

\begin{tabular}{|c|c|c|c|c|c|}
\hline \multirow{3}{*}{$\begin{array}{l}\text { BT } \\
\text { (s) }\end{array}$} & \multicolumn{4}{|c|}{$\mathrm{UV}_{254}$ Absorbance $\left(\mathrm{cm}^{-1}\right)$} & \multirow{3}{*}{$\begin{array}{c}\text { Average } \\
\text { Treatment } \\
\text { Efficiency } \\
\text { (\%) }\end{array}$} \\
\hline & \multicolumn{2}{|c|}{ Feed Water } & \multicolumn{2}{|c|}{ Treated Water } & \\
\hline & Range & Average & Range & Average & \\
\hline $\mathrm{NBW} *$ & $0.322 \sim 0.324$ & 0.323 & $0.038 \sim 0.044$ & 0.042 & 87.1 \\
\hline 6 & $0.311 \sim 0.313$ & 0.313 & $0.031 \sim 0.038$ & 0.035 & 89.0 \\
\hline 10 & $0.317 \sim 0.325$ & 0.263 & $0.037 \sim 0.046$ & 0.041 & 87.3 \\
\hline 15 & $0.238 \sim 0.303$ & 0.246 & $0.040 \sim 0.045$ & 0.042 & 84.2 \\
\hline 20 & $0.249 \sim 0.331$ & 0.264 & $0.016 \sim 0.023$ & 0.020 & 92.4 \\
\hline 30 & $0.341 \sim 0.349$ & 0.345 & $0.041 \sim 0.054$ & 0.045 & 86.9 \\
\hline
\end{tabular}

The $U_{254}$ absorbance of real lake water was in the range of $0.041-0.045 \mathrm{~cm}^{-1}$ (average $0.043 \mathrm{~cm}^{-1}$ ), as published by our group [27]. That of HA $10 \mathrm{mg} / \mathrm{L}$ solution in Table 4 was $0.246-0.345 \mathrm{~cm}^{-1}$ (average $0.300 \mathrm{~cm}^{-1}$ ), which was 7.00 times higher than that of real lake water. Therefore, the HA solution used in this research could modify the extreme condition of lake water quality.

\subsection{Influence of Water Backwashing Period (BP) on Membrane Fouling and Treatment Efficiency}

As compared in Figure 5a, the resistances of membrane fouling $\left(R_{f}\right)$ were maintained the highest and almost overlapped at BP 2 and 4 min condition during 180 min's operation time. The $\mathrm{R}_{\mathrm{f}}$ showed suddenly the lowest values at BP $6 \mathrm{~min}$, which means the BP 6 min could be the optimal water backwashing period in this combined water treatment process of tubular alumina MF (NCMT-7231) and PP beads. However, the $\mathrm{R}_{\mathrm{f}}$ increased dramatically at BP $8 \mathrm{~min}$ and decreased at BP $10 \mathrm{~min}$, which proved that too longer BP more than 6 min could not be efficient to inhibit the membrane fouling. In addition, the $R_{f}$ values increased a little at no water backwashing (NBW), which means too short or longer BP conditions could not reduce the membrane fouling in this combined water treatment.

As presented in Figure $5 \mathrm{~b}$, the dimensionless permeate flux $\left(\mathrm{J} / \mathrm{J}_{0}\right)$, overlapped almost and maintained the lowest values at BP 2, 4, and $8 \mathrm{~min}$. However, the $\mathrm{J} / \mathrm{J}_{0}$ increased dramatically high at BP 6 min, because the membrane fouling was inhibited effectively by proper water backwashing period and permeate flux could maintain high values. Furthermore, it increased a little at BP $10 \mathrm{~min}$, and abruptly high at NBW condition. This phenomenon could be explained by comparing the $\mathrm{J}_{0}$ as arranged in Table 5 . Because the $\mathrm{J}_{0}$ values dropped suddenly at BP 10 min and NBW by longer BP condition, the $\mathrm{J} / \mathrm{J}_{0}$ increased dramatically.

As arranged in Table 5, the resistance of membrane $\left(R_{m}\right)$ was regulated at almost constant value by combustion at a furnace and washing by acid and alkali solution, as mentioned in Section 2. Materials and Methods. The final $R_{f}\left(R_{f, 180}\right)$ value after 180 min's operation at BP 2 min was $4.877 \times 10^{9} \mathrm{~kg} / \mathrm{m}^{2} \mathrm{~s}$, which was 1.24 times higher than $3.931 \times 10^{9} \mathrm{~kg} / \mathrm{m}^{2} \mathrm{~s}$ at BP $6 \mathrm{~min}$. Furthermore, the total treated volume $\left(\mathrm{V}_{\mathrm{T}}\right)$ showed the highest $3.10 \mathrm{~L}$ at BP 6 min, which was 1.57 times higher than $2.56 \mathrm{~L}$ at BP $2 \mathrm{~min}$. In conclusion, the optimal BP condition could be $6 \mathrm{~min}$, because of the minimum membrane fouling and the maximum total treated volume in this combined water treatment process of tubular alumina MF (NCMT-7231) and PP beads. 


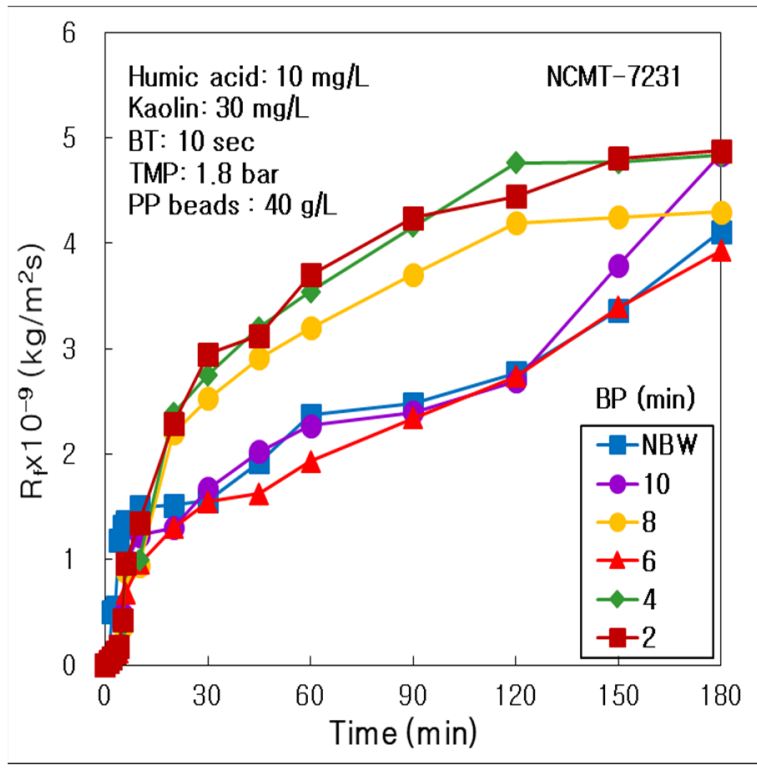

(a)

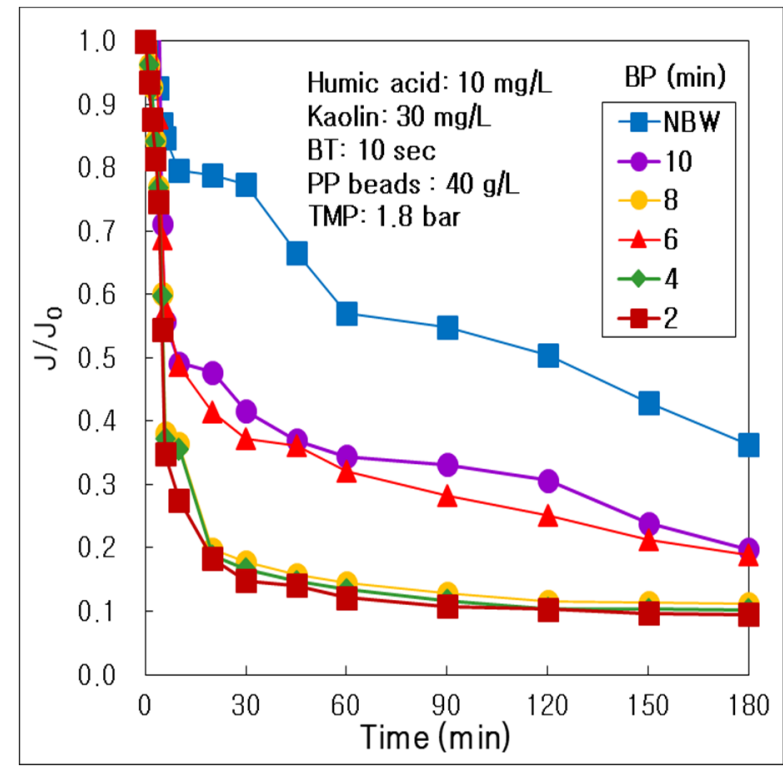

(b)

Figure 5. Influence of water backwashing period (BP) in the combined process of tubular alumina MF (NCMT-7231) and PP beads with UV irradiation and periodic water backwashing: (a) Resistance of membrane fouling; (b) Dimensionless permeate flux.

Table 5. Influence of water backwashing period on filtration factors in the combined process of tubular alumina MF (NCMT-7231) membrane and PP beads with periodic water backwashing.

\begin{tabular}{ccccccc}
\hline BP $(\mathbf{m i n})$ & NBW & $\mathbf{1 0}$ & $\mathbf{8}$ & $\mathbf{6}$ & $\mathbf{4}$ & $\mathbf{2}$ \\
\hline $\mathrm{R}_{\mathrm{m}} \times 10^{-9}\left(\mathrm{~kg} / \mathrm{m}^{2} \mathrm{~s}\right)$ & 0.694 & 0.626 & 0.528 & 0.602 & 0.534 & 0.508 \\
$\mathrm{R}_{\mathrm{b}} \times 10^{-9}\left(\mathrm{~kg} / \mathrm{m}^{2} \mathrm{~s}\right)$ & 1.050 & 0.566 & 0.017 & 0.316 & 0.017 & 0.005 \\
$\mathrm{R}_{\mathrm{f}, 180 \times 10^{-9}\left(\mathrm{~kg} / \mathrm{m}^{2} \mathrm{~s}\right)}$ & 4.112 & 4.849 & 4.299 & 3.931 & 4.834 & 4.877 \\
$\mathrm{R}_{\mathrm{if}} \times 10^{-9}\left(\mathrm{~kg} / \mathrm{m}^{2} \mathrm{~s}\right)$ & 0.719 & 0.465 & 0.156 & 0.283 & 0.098 & 0.040 \\
$\mathrm{R}_{\mathrm{rf}} \times 10^{-9}\left(\mathrm{~kg} / \mathrm{m}^{2} \mathrm{~s}\right)$ & 3.393 & 4.384 & 4.143 & 3.648 & 4.736 & 4.837 \\
$\mathrm{~J}_{0}\left(\mathrm{~L} / \mathrm{m}^{2} \mathrm{hr}\right)$ & 364 & 533 & 1166 & 692 & 1152 & 1237 \\
$\mathrm{~J}_{180}\left(\mathrm{~L} / \mathrm{m}^{2} \mathrm{hr}\right)$ & 132 & 105 & 131 & 131 & 118 & 118 \\
$\mathrm{~J}_{180} / \mathrm{J}_{0}$ & 0.363 & 0.197 & 0.112 & 0.189 & 0.102 & 0.095 \\
$\mathrm{~V}_{\mathrm{T}}(\mathrm{L})$ & 3.01 & 2.63 & 2.72 & 3.10 & 2.56 & 2.56 \\
\hline${ }^{*}$ no backwashing & & & & & &
\end{tabular}

In bar graphs of Figure 6, resistances of membrane, boundary layer, final, irreversible and reversible membrane fouling $\left(R_{m}, R_{b}, R_{f, 180}, R_{i f}, R_{r f}\right)$ were compared clearly. The $R_{r f}$ was a major membrane fouling in this combined water treatment process. It proved that most of the membrane fouling could be easily removed by physical cleaning at the BP influence experiment, which matched with the result of BT influence. In addition, the $\mathrm{R}_{\mathrm{b}}$ decreased dramatically as decreasing BP from NBW to BP 2 min. It means that the more frequent water backwashing could weaken the boundary layer of concentration polarization on the membrane surface excellently.

As arranged in Table 6, the treatment efficiency of turbidity did not have a constant trend, depending on BP; however, the highest efficiency was $99.7 \%$ at BP 4 and 6 min. Furthermore, the lowest value showed $98.4 \%$ at NBW, but the difference between the highest and lowest efficiency was just $1.3 \%$. It proved that the turbidity could be powerfully treated over $98.4 \%$ by microfiltration and PP beads adsorption, independent of water BP condition in the combined process of tubular alumina MF and PP beads. In our previous work [25], for the combined process of tubular carbon fiber UF and pure PP beads, the turbidity treatment efficiency was a little higher $99.7 \%$ than $98.4 \%$ of this research, because MF had a larger pore size than UF. 


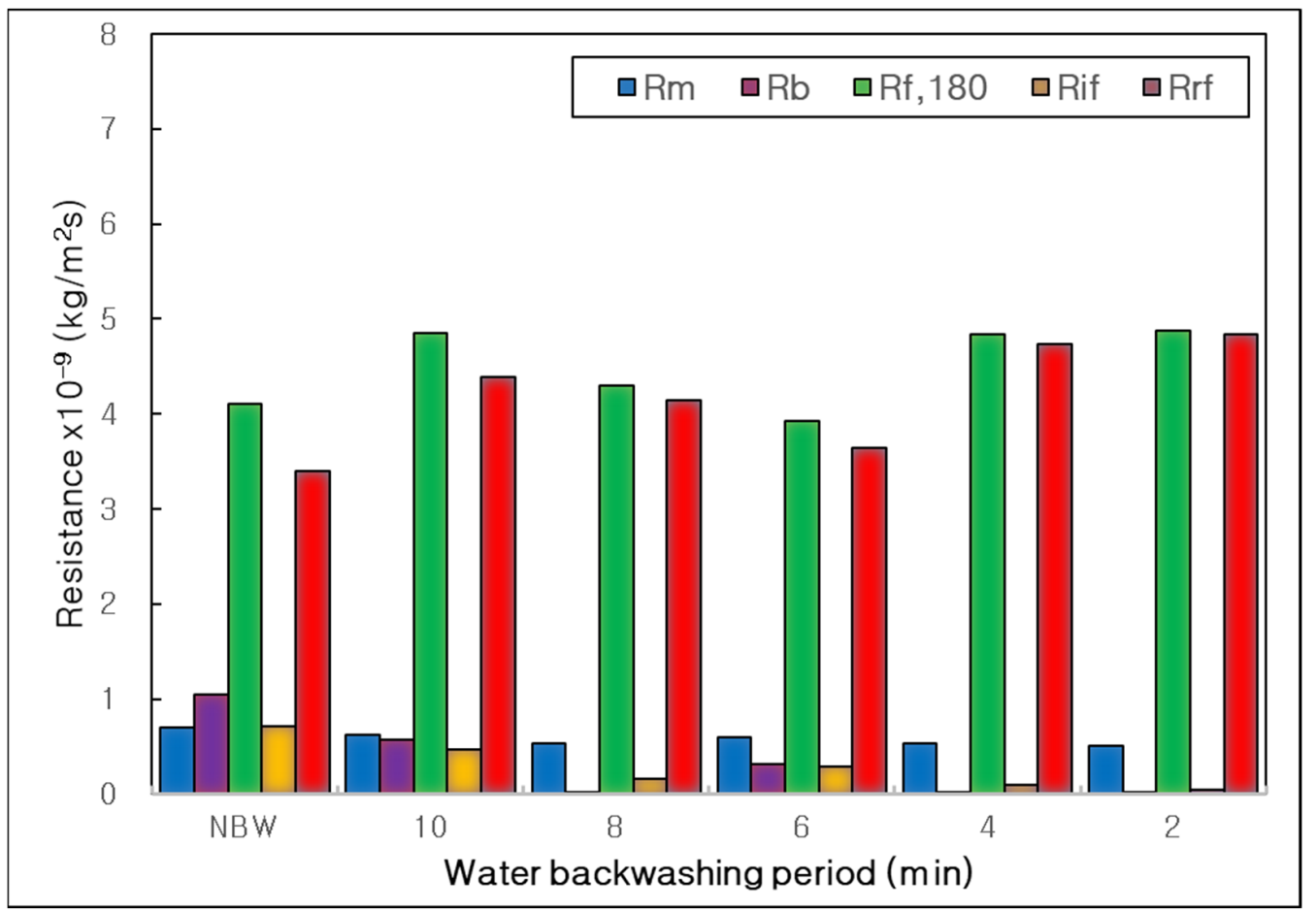

Figure 6. Influence of water backwashing period on resistances of membrane, boundary layer, final, irreversible and reversible membrane fouling $\left(R_{m}, R_{b}, R_{f, 180}, R_{i f}, R_{r f}\right)$ in the combined process of tubular alumina MF (NCMT-7231) and PP beads with UV irradiation and periodic water backwashing.

Table 6. Water quality and treatment efficiency of turbidity in the combined process of tubular alumina MF (NCMT-7231) and PP beads for the influence of water backwashing period.

\begin{tabular}{cccccc}
\hline \multirow{2}{*}{$\begin{array}{c}\text { BP } \\
(\mathbf{m i n})\end{array}$} & \multicolumn{4}{c}{ Feed Water } & \multicolumn{2}{c}{ Turbidity (NTU) } & \multirow{2}{*}{$\begin{array}{c}\text { Average } \\
\text { Treatment } \\
\text { Efficiency } \\
\end{array}$} & Range & Average & Range & Average & \begin{tabular}{c} 
T\%) \\
\cline { 2 - 5 }
\end{tabular} \\
\cline { 2 - 5 } NBW $^{*}$ & $41.1 \sim 43.5$ & 42.2 & $0.623 \sim 0.723$ & 0.687 & 98.4 \\
10 & $40.3 \sim 43.6$ & 41.7 & $0.498 \sim 0.612$ & 0.547 & 98.7 \\
8 & $47.4 \sim 49.2$ & 48.1 & $0.202 \sim 0.262$ & 0.299 & 99.5 \\
6 & $45.8 \sim 61.3$ & 52.6 & $0.091 \sim 0.313$ & 0.176 & 99.7 \\
4 & $47.2 \sim 51.5$ & 49.6 & $0.136 \sim 0.239$ & 0.173 & 99.7 \\
2 & $43.6 \sim 51.9$ & 47.9 & $0.523 \sim 0.832$ & 0.694 & 98.6 \\
\hline
\end{tabular}

* no backwashing.

As compared in Table 7, the treatment efficiency of $U_{254}$ absorbance (DOM) did not present a constant trend like that of turbidity. The maximal efficiency showed $94.3 \%$ at BP $8 \mathrm{~min}$, and the lowest value was $91.6 \%$ at BP 4 min; however, the gap of the two values was $2.7 \%$, which was a little higher than that of turbidity. It means that DOM could be excellently rejected over $91.6 \%$ by PP beads adsorption and UV photo-oxidation in the combined water treatment process. The DOM treatment efficiencies of PP beads adsorption and UV photo-oxidation were $5.4 \%$ and $0.7 \%$ respectively as published by our group in Desal. Water Treat. [25]. Application of photocatalysis contributed to the improvement of the permeate flux compared with photolysis by 16-35\% using a ceramic membrane with $\mathrm{ZrO}_{2}$ separation layer [11]. However, there was no data for the effect of photocatalysis on treatment efficiency in this research. 
Table 7. Water quality and treatment efficiency of DOM ( $\mathrm{UV}_{254}$ absorbance) in the combined process of tubular alumina MF (NCMT-7231) and PP beads for the influence of water backwashing period.

\begin{tabular}{|c|c|c|c|c|c|}
\hline \multirow{3}{*}{$\begin{array}{c}\text { BP } \\
(\mathrm{min})\end{array}$} & \multicolumn{4}{|c|}{$\mathrm{UV}_{254}$ Absorbance $\left(\mathrm{cm}^{-1}\right)$} & \multirow{3}{*}{$\begin{array}{c}\text { Average } \\
\text { Treatment } \\
\text { Efficiency } \\
(\%)\end{array}$} \\
\hline & \multicolumn{2}{|c|}{ Feed Water } & \multicolumn{2}{|c|}{ Treated Water } & \\
\hline & Range & Average & Range & Average & \\
\hline NBW * & $0.226 \sim 0.236$ & 0.234 & $0.017 \sim 0.019$ & 0.018 & 92.4 \\
\hline 10 & $0.221 \sim 0.249$ & 0.236 & $0.012 \sim 0.018$ & 0.015 & 93.7 \\
\hline 8 & $0.021 \sim 0.304$ & 0.299 & $0.011 \sim 0.022$ & 0.017 & 94.3 \\
\hline 6 & $0.247 \sim 0.351$ & 0.315 & $0.013 \sim 0.036$ & 0.021 & 93.4 \\
\hline 4 & $0.211 \sim 0.341$ & 0.289 & $0.021 \sim 0.029$ & 0.024 & 91.6 \\
\hline 2 & $0.288 \sim 0.315$ & 0.297 & $0.009 \sim 0.038$ & 0.018 & 93.8 \\
\hline
\end{tabular}

* no backwashing.

\subsection{Influence of Membrane Shape (Tubular or Seven Channel) on Membrane Fouling and Treatment Efficiency}

To investigate the influence of membrane shape, the resistance of membrane fouling $\left(\mathrm{R}_{\mathrm{f}}\right)$ was compared depending on the water backwashing period $(\mathrm{BP})$ in the combined process of seven channel alumina MF (HC04) and pure PP beads, as presented in Figure 7a. The $R_{\mathrm{f}}$ values maintained the lowest at BP 2 min and the highest at BP 10 min during all of 180 min's operation. Those showed a dramatic trend to increase as increasing BP from 2 to $10 \mathrm{~min}$; however, those decreased a little at NBW condition. It means that water BP $10 \mathrm{~min}$ could not reduce the membrane fouling in this combined process. Finally, the BP 2 min could be the optimal water backwashing period in the combined process of seven channel alumina MF and PP beads. It was an obviously different trend, comparing that the $\mathrm{R}_{\mathrm{f}}$ at $\mathrm{BP}$ 6 min was lowest in this combined process of tubular alumina MF (NCMT-7231) and PP beads, because of different membrane shape, as shown in Figure 5a.

As presented in Figure $7 \mathrm{~b}$ to investigate the BP influence on relative permeate flux, the $\mathrm{J} / \mathrm{J}_{0}$ values showed a decreasing trend dramatically through all of the operation time, as increasing BP from 2 to $10 \mathrm{~min}$; however, those at NBW increased a little higher than those of BP $10 \mathrm{~min}$. It proved that the BP of $10 \mathrm{~min}$ could be a too long period to inhibit the membrane fouling in this combined process using seven channel MF. As summarized in Table 8, the final $\mathrm{J}_{180} / \mathrm{J}_{0}$ after 180 min's operation at BP 2 min showed the highest 0.422 , which was 2.14 times higher than the lowest 0.197 at BP $8 \mathrm{~min}$. It proved that the highest permeate flux could be acquired at BP 2, which was the most frequent water backwashing condition because the membrane fouling could be inhibited by frequent backwashing. In conclusion, the maximum $\mathrm{V}_{\mathrm{T}}$ of $5.79 \mathrm{~L}$ could be acquired at $\mathrm{BP} 2 \mathrm{~min}$, because the permeate flux could sustain highly through all of $180 \mathrm{~min}$ 's operation. The $\mathrm{J} / \mathrm{J}_{0}$ overlapped almost and maintained the lowest values at BP 2, 4, and $8 \mathrm{~min}$ in the combined process using tubular MF, as presented in Figure $5 \mathrm{~b}$. However, the $\mathrm{J} / \mathrm{J}_{0}$ increased dramatically high at BP 6 min. This dissimilar trend was happened, because the seven channel MF membrane could have a different membrane fouling mechanism, compared with tubular MF. 


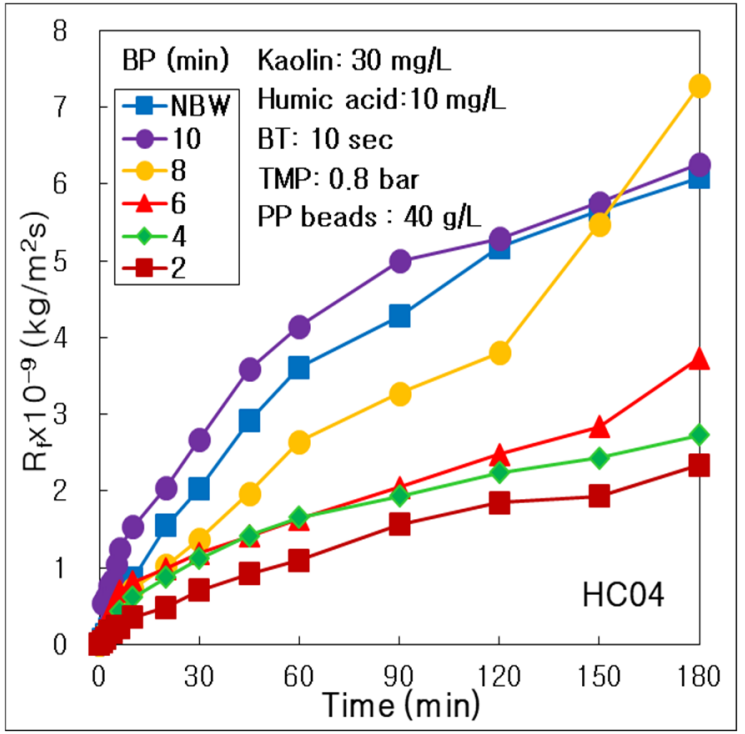

(a)

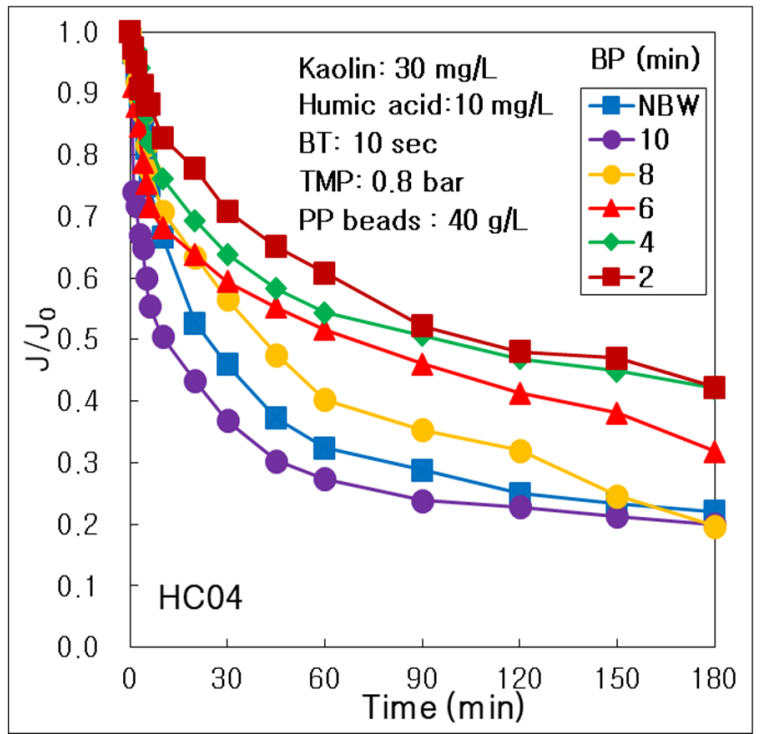

(b)

Figure 7. Influence of water backwashing period (BP) in the combined process of seven channel alumina MF (HC04) and PP beads with UV irradiation and periodic water backwashing: (a) Resistance of membrane fouling; (b) Dimensionless permeate flux.

Table 8. Influence of water backwashing period on filtration factors in the combined process of seven channel alumina MF (HC04) membrane and PP beads with periodic water backwashing.

\begin{tabular}{ccccccc}
\hline BP $(\mathbf{m i n})$ & NBW * & $\mathbf{1 0}$ & $\mathbf{8}$ & $\mathbf{6}$ & $\mathbf{4}$ & $\mathbf{2}$ \\
\hline $\mathrm{R}_{\mathrm{m}} \times 10^{-9}\left(\mathrm{~kg} / \mathrm{m}^{2} \mathrm{~s}\right)$ & 1.019 & 1.052 & 1.041 & 1.025 & 1.019 & 1.030 \\
$\mathrm{R}_{\mathrm{b}} \times 10^{-9}\left(\mathrm{~kg} / \mathrm{m}^{2} \mathrm{~s}\right)$ & 0.710 & 0.511 & 0.748 & 0.720 & 0.962 & 0.682 \\
$\mathrm{R}_{\mathrm{f}, 180} \times 10^{-9}\left(\mathrm{~kg} / \mathrm{m}^{2} \mathrm{~s}\right)$ & 6.086 & 6.264 & 7.287 & 3.733 & 2.732 & 2.342 \\
$\mathrm{R}_{\mathrm{fi}} \times 10^{-9}\left(\mathrm{~kg} / \mathrm{m}^{2} \mathrm{~s}\right)$ & 0.797 & 0.741 & 0.717 & 0.673 & 0.456 & 0.309 \\
$\mathrm{R}_{\mathrm{rf}} \times 10^{-9}\left(\mathrm{~kg} / \mathrm{m}^{2} \mathrm{~s}\right)$ & 5.288 & 5.523 & 6.571 & 3.060 & 2.276 & 2.033 \\
$\mathrm{~J}_{0}\left(\mathrm{~L} / \mathrm{m}^{2} \mathrm{hr}\right)$ & 163 & 181 & 158 & 162 & 142 & 165 \\
$\mathrm{~J}_{180}\left(\mathrm{~L} / \mathrm{m}^{2} \mathrm{hr}\right)$ & 36 & 36 & 31 & 52 & 60 & 70 \\
$\mathrm{~J}_{180} / \mathrm{J}_{0}$ & 0.221 & 0.200 & 0.197 & 0.319 & 0.420 & 0.422 \\
$\mathrm{~V}_{\mathrm{T}}(\mathrm{L})$ & 3.60 & 3.28 & 3.98 & 4.95 & 4.83 & 5.79 \\
\hline * & & & & & &
\end{tabular}

As presented in Table 8, the final $R_{\mathrm{f}}\left(R_{\mathrm{f}, 180}\right)$ showed the highest $7.287 \times 10^{9} \mathrm{~kg} / \mathrm{m}^{2} \mathrm{~s}$ at BP $8 \mathrm{~min}$, which was 3.11 times higher than the lowest $2.342 \times 10^{9} \mathrm{~kg} / \mathrm{m}^{2} \mathrm{~s}$ at BP $2 \mathrm{~min}$. It means that a longer BP than 8 min could not inhibit the membrane fouling by water backwashing in the combined process using tubular MF. However, in the combined process using tubular MF, the $R_{f, 180}$ value at BP 2 min was the maximum, and that of BP 6 min was the minimum, as arranged in Section 3.2, because of different membrane shapes. It proved that the water backwashing period should be adjusted, depending on the membrane shape such as tubular or multi-channel. In addition, the maximal $7.287 \times 10^{9} \mathrm{~kg} / \mathrm{m}^{2} \mathrm{~s}$ of $\mathrm{R}_{\mathrm{f}, 180}$ using seven channel MF was much higher than $4.849 \times 10^{9} \mathrm{~kg} / \mathrm{m}^{2} \mathrm{~s}$ of tubular MF; however, the minimal $2.342 \times 10^{9} \mathrm{~kg} / \mathrm{m}^{2} \mathrm{~s}$ of seven channel MF was lower than $3.931 \times 10^{9} \mathrm{~kg} / \mathrm{m}^{2} \mathrm{~s}$ of tubular MF. It proved that water backwashing could inhibit the membrane fouling better for seven channel membranes than a tubular membrane.

In the bar graphs in Figure 8, all of the resistances were compared to investigate each portion of total resistance. The $\mathrm{R}_{\mathrm{rf}}$ showed a major resistance of total membrane fouling, and the $\mathrm{R}_{\mathrm{if}}$ was a minor one, similar to the results of $\mathrm{BT}$ and $\mathrm{BP}$ for combined process using tubular MF. Moreover, the $\mathrm{R}_{\mathrm{f}, 180}$ and $\mathrm{R}_{\mathrm{rf}}$ decreased dramatically as decreasing BP from 8 to $2 \mathrm{~min}$; however, the $\mathrm{R}_{\mathrm{if}}$ showed a decreasing trend obviously, as decreasing BP from NBW to $2 \mathrm{~min}$. It means that the more frequent water backwashing could be more effective 
to control the membrane fouling, especially the irreversible fouling, for seven channel membrane than tubular membrane. Furthermore, the $\mathrm{R}_{\mathrm{b}}$ did not show a constant trend, depending on BP; however, it decreased dramatically as shorter BP condition from NBW to BP 2 min in the combined process using tubular MF, because of different membrane shapes.

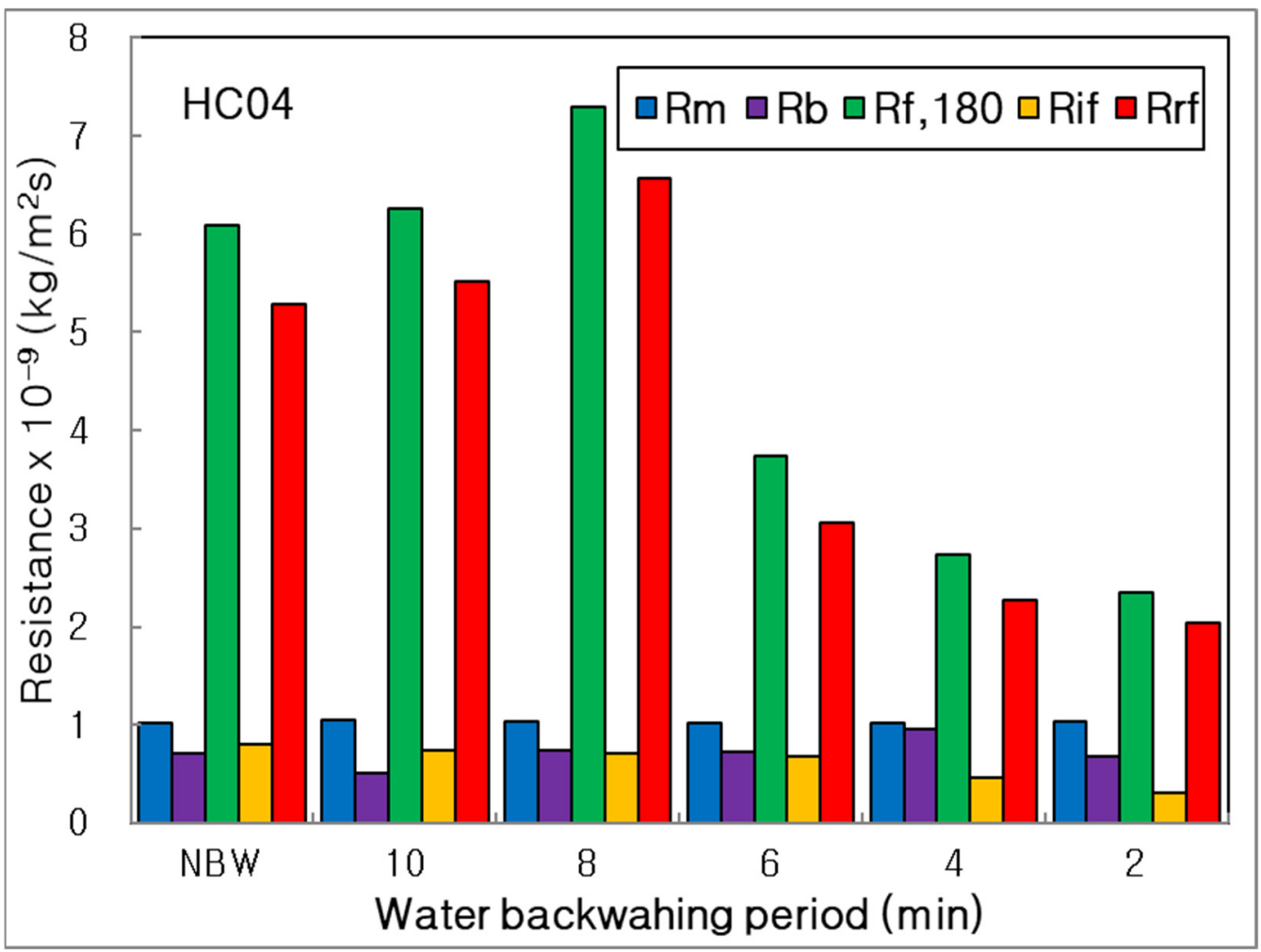

Figure 8. Influence of water backwashing period on resistances of membrane, boundary layer, final, irreversible and reversible membrane fouling $\left(\mathrm{R}_{\mathrm{m}}, \mathrm{R}_{\mathrm{b}}, \mathrm{R}_{\mathrm{f}, 180}, \mathrm{R}_{\mathrm{if}}, \mathrm{R}_{\mathrm{rf}}\right)$ in the combined process of seven channel alumina MF (HC04) and PP beads with UV irradiation and periodic water backwashing.

As summarized in Table 9, the treatment efficiency of turbidity showed almost constant in the range of $99.0 \%$ and $99.1 \%$. In the combined process using tubular $\mathrm{MF}$, the highest efficiency was $99.7 \%$ at BP 4 and $6 \mathrm{~min}$, and the lowest $98.4 \%$ at NBW, as arranged in Table 6 . The highest $99.7 \%$ for tubular MF was a little higher than $99.1 \%$ of seven channel MF because the tubular MF had a smaller pore size $0.1 \mu \mathrm{m}$ than $0.4 \mu \mathrm{m}$ of seven channel MF.

Table 9. Water quality and treatment efficiency of turbidity in the combined process of seven channel alumina MF (HC04) and PP beads for the influence of water backwashing period.

\begin{tabular}{|c|c|c|c|c|c|}
\hline \multirow{3}{*}{$\begin{array}{c}\text { BP } \\
(\mathrm{min})\end{array}$} & \multicolumn{4}{|c|}{ Turbidity (NTU) } & \multirow{3}{*}{$\begin{array}{c}\text { Average } \\
\text { Treatment } \\
\text { Efficiency } \\
(\%)\end{array}$} \\
\hline & \multicolumn{2}{|c|}{ Feed Water } & \multicolumn{2}{|c|}{ Treated Water } & \\
\hline & Range & Average & Range & Average & \\
\hline NBW * & $56.9 \sim 61.5$ & 59.3 & $0.506 \sim 0.637$ & 0.567 & 99.1 \\
\hline 10 & $56.5 \sim 61.1$ & 58.5 & $0.482 \sim 0.658$ & 0.557 & 99.1 \\
\hline 8 & $67.2 \sim 72.8$ & 69.8 & $0.674 \sim 0.867$ & 0.752 & 99.1 \\
\hline 6 & $72.8 \sim 75.1$ & 73.9 & $0.601 \sim 0.735$ & 0.677 & 99.1 \\
\hline 4 & $68.2 \sim 71.8$ & 70.0 & $0.574 \sim 0.689$ & 0.647 & 99.1 \\
\hline 2 & $76.4 \sim 78.2$ & 77.2 & $0.632 \sim 0.963$ & 0.805 & 99.0 \\
\hline
\end{tabular}

* no backwashing.

As compared in Table 10, the treatment efficiency of DOM did not show a constant trend, depending on BP. The highest efficiency showed $82.4 \%$ at BP $6 \mathrm{~min}$, and the lowest was $80.1 \%$; however, the difference between the two values was only $2.3 \%$. It proved that 
the DOM treatment was not affected by the water backwashing period in the combined process using seven channel MF. For the process using tubular MF as shown in Table 7, the DOM treatment efficiency did not present a constant trend like this result. The maximal efficiency showed $94.3 \%$ at BP $8 \mathrm{~min}$, and the lowest value was $91.6 \%$ at BP $4 \mathrm{~min}$, which was higher than that of seven channel MF. It means that the tubular shape membrane could be more excellent to treat DOM than seven channel membrane.

Table 10. Water quality and treatment efficiency of $\mathrm{DOM}\left(\mathrm{UV}_{254}\right.$ absorbance $)$ in the combined process of seven channel alumina MF (HC04) and PP beads for the influence of water backwashing period.

\begin{tabular}{|c|c|c|c|c|c|}
\hline \multirow{3}{*}{$\begin{array}{c}\text { BP } \\
(\mathrm{min})\end{array}$} & \multicolumn{4}{|c|}{$\mathrm{UV}_{254}$ Absorbance $\left(\mathrm{cm}^{-1}\right)$} & \multirow{3}{*}{$\begin{array}{c}\text { Average } \\
\text { Treatment } \\
\text { Efficiency } \\
(\%)\end{array}$} \\
\hline & \multicolumn{2}{|c|}{ Feed Water } & \multicolumn{2}{|c|}{ Treated Water } & \\
\hline & Range & Average & Range & Average & \\
\hline $\mathrm{NBW}^{*}$ & $0.524 \sim 0.631$ & 0.578 & $0.097 \sim 0.127$ & 0.111 & 80.8 \\
\hline 10 & $0.441 \sim 0.513$ & 0.482 & $0.081 \sim 0.114$ & 0.096 & 80.2 \\
\hline 8 & $0.583 \sim 0.608$ & 0.598 & $0.108 \sim 0.120$ & 0.114 & 80.9 \\
\hline 6 & $0.584 \sim 0.624$ & 0.609 & $0.089 \sim 0.121$ & 0.107 & 82.4 \\
\hline 4 & $0.541 \sim 0.609$ & 0.577 & $0.098 \sim 0.119$ & 0.108 & 81.2 \\
\hline 2 & $0.524 \sim 0.584$ & 0.560 & $0.101 \sim 0.122$ & 0.111 & 80.1 \\
\hline
\end{tabular}

* no backwashing.

\section{Conclusions}

In this research, the optimal water backwashing was investigated in the combined water treatment process of alumina MF and pure PP beads. Additionally, the influence of membrane shape (tubular of seven channel) was examined, depending on the water backwashing period. The results of water backwashing were compared with those of the previous study [24,25] in the combined process of the tubular carbon fiber UF and photocatalyst-coated PP beads or pure PP beads. In conclusion, the following results could be found out from these investigations.

(1) The dimensionless permeate flux $\left(\mathrm{J}_{180} / \mathrm{J}_{0}\right)$ after $180 \mathrm{~min}$ 's operation at BT $30 \mathrm{~s}$ showed the highest value. However, the total treated water volume $\left(\mathrm{V}_{\mathrm{T}}\right)$ had the highest at BT $20 \mathrm{~s}$, because J maintained higher from 10 to 30 min's operation than those of other BT conditions. Finally, the optimal BT condition could be $20 \mathrm{~s}$ in the combined water treatment process, because of the maximum $\mathrm{V}_{\mathrm{T}}$ in our experimental BT conditions. In the previous work [24], for the combined process of tubular carbon fiber UF and photocatalyst-coated PP beads, the maximum $\mathrm{V}_{\mathrm{T}}$ could be acquired at BT $30 \mathrm{~s}$, which agreed with this result of the combined process of tubular alumina MF and pure PP beads.

(2) The final $R_{f}\left(R_{f, 180}\right)$ value after 180 min's operation at BP 2 min was the highest at BP $6 \mathrm{~min}$. Furthermore, the $\mathrm{V}_{\mathrm{T}}$ showed the highest $3.10 \mathrm{~L}$ at BP $6 \mathrm{~min}$. In conclusion, the optimal BP condition could be $6 \mathrm{~min}$, because of the minimum membrane fouling and the maximum total treated volume in this combined water treatment process of tubular alumina MF and PP beads.

(3) The resistance of reversible membrane fouling $\left(R_{r f}\right)$ showed a major resistance of total membrane fouling, and that of irreversible membrane fouling $\left(R_{i f}\right)$ was a minor one, in the combined process using tubular or seven channel MF. The $\mathrm{R}_{\mathrm{if}}$ showed a decreasing trend obviously, as decreasing BP from NBW to 2 min for seven channel MF. It means that the more frequent water backwashing could be more effective to control the membrane fouling, especially irreversible fouling, for seven channel membranes than tubular membranes.

Author Contributions: Experiments, H.C., G.Y. and M.K.; writing-review and editing, J.Y.P. All authors have read and agreed to the published version of the manuscript.

Funding: This research funding was reinforced by Hallym University, 2020 (HRF-202010-004). 


\section{Institutional Review Board Statement: Not applicable.}

Informed Consent Statement: Not applicable.

Data Availability Statement: Not applicable.

Conflicts of Interest: The authors declare no conflict of interest.

\section{References}

1. Meng, F.G.; Chae, S.R.; Drews, A.; Kraume, M.; Shin, H.S.; Yang, F. Recent advances in membrane bioreactors (MBRs): Membrane fouling and membrane material. Water Res. 2009, 43, 1489-1512. [CrossRef] [PubMed]

2. Liu, C.X.; Zhang, D.R.; He, Y.; Zhao, X.S.; Bai, R. Modification of membrane surface for anti-biofouling performance: Effect of anti-adhesion and anti-bacterial approaches. J. Membr. Sci. 2010, 346, 121-130. [CrossRef]

3. Cui, X.; Choo, K.-H. Natural Organic Matter Removal and Fouling Control in Low-Pressure Membrane Filtration for Water Treatment. Environ. Eng. Res. 2014, 19, 1-8. [CrossRef]

4. Manamperuma, L.D.; Vik, E.A.; Benjamin, M.; Cai, Z.; Skjefstad, J. Effects of a novel adsorbent on membrane fouling by natural organic matter in drinking water treatment. Membranes 2019, 9, 151. [CrossRef]

5. Gao, Y.; Zhang, Y.; Dudek, M.; Qin, J.; Øye, G.; Østerhus, S.W. A multivariate study of backpulsing for membrane fouling mitigation in produced water treatment. J. Environ. Chem. Eng. 2020, 2020, 104839. [CrossRef]

6. Cakl, J.; Bauer, I.; Doleček, P.; Mikulášek, P. Effects of backflushing conditions on permeate flux in membrane crossflow microfiltration of oil emulsion. Desalination 2000, 127, 189-198. [CrossRef]

7. Abadi, S.R.H.; Sebzari, M.R.; Hemati, M.; Rekabdar, F.; Mohammadi, T. Ceramic membrane performance in microfiltration of oily wastewater. Desalination 2011, 265, 222-228. [CrossRef]

8. Tian, J.; Wu, C.; Yu, H.; Gao, S.; Li, G.; Cui, F.; Qu, F. Applying ultraviolet/persulfate (UV/PS) pre-oxidation for controlling ultrafiltration membrane fouling by natural organic matter (NOM) in surface water. Water Res. 2018, 132, 190-199. [CrossRef]

9. Marconnet, C.; Houari, A.; Seyer, D.; Djafer, M.; Coriton, G.; Heim, V.; Martino, P.D. Membrane biofouling control by UV irradiation. Desalination 2011, 276, 75-81. [CrossRef]

10. Kusworo, T.D.; Utomo, D.P. Performance evaluation of double stage process using nano hybrid $\mathrm{PES} / \mathrm{SiO}_{2}-\mathrm{PES}$ membrane and PES/ZnO-PES membranes for oily waste water treatment to clean water. J. Environ. Chem. Eng. 2017, 5, 6077-6086. [CrossRef]

11. Szymański, K.; Morawski, A.W.; Mozia, S. Surface water treatment in hybrid systems coupling advanced oxidation processes and ultrafiltration using ceramic membrane. Desalinat. Water Treat. 2017, 64, 302-306. [CrossRef]

12. Hofs, B.; Ogier, J.; Vries, D.; Beerendonk, E.F.; Cornelissen, E.R. Comparison of ceramic and polymeric membrane permeability and fouling using surface water. Sep. Purif. Technol. 2011, 79, 365-374. [CrossRef]

13. Chen, M.; Heijman, S.G.J.; Rietveld, L.C. State-of-the-art ceramic membranes for oily wastewater treatment: Modification and application. Membranes 2021, 11, 888. [CrossRef]

14. Liu, P.; Liu, J.; Wang, Z.; Jiao, Y.; Bie, A.; Xia, J. Application of inorganic ceramic membrane in treatment of emulsion wastewater. Oxidat. Commun. 2016, 39, 2753-2757.

15. Zhang, X.; Fan, L.; Roddick, F.A. Influence of the characteristics of soluble algal organic matter released from Microcystis aeruginosa on the fouling of a ceramic microfiltration membrane. J. Membr. Sci. 2013, 425, 23-29. [CrossRef]

16. Zhang, X.; Fan, L.; Roddick, F.A. Impact of the interaction between aquatic humic substances and algal organic matter on the fouling of a ceramic microfiltration membrane. Membranes 2018, 8, 7. [CrossRef]

17. Benito, A.; Penadés, A.; Lliberia, J.L.; Gonzalez-Olmos, R. Degradation pathways of aniline in aqueous solutions during electro-oxidation with BDD electrodes and $\mathrm{UV} / \mathrm{H}_{2} \mathrm{O}_{2}$ treatment. Chemosph. 2017, 166, 230-237. [CrossRef]

18. Khuzwayo, Z.; Chirwa, E.M.N. Analysis of catalyst photo-oxidation selectivity in the degradation of polyorganochlorinated pollutants in batch systems using UV and UV/TiO 2 . South Afr. J. Chem. Eng. 2017, 23, 17-25. [CrossRef]

19. Milelli, D.; Lemont, F.; Ruffel, L.; Barral, T.; Marchand, M. Thermo- and photo-oxidation reaction scheme in a treatment system using submerged plasma. Chem. Eng. J. 2017, 317, 1083-1091. [CrossRef]

20. Morgan, A.; Cocca, M.; Vega, K.; Fleischer, A.; Gupta, S.K.; Mehan, M.; Takacs, G.A. Vacuum UV photo-oxidation of poly(ethylene terephthalate). J. Adhes. Sci. Technol. 2017, 31, 2542-2554. [CrossRef]

21. Semitsoglou-Tsiapou, S.; Templeton, M.R.; Graham, N.J.D.; Hernández Leal, L.; Martijn, B.J.; Royce, A.; Kruithof, J.C. Low pressure $\mathrm{UV} / \mathrm{H}_{2} \mathrm{O}_{2}$ treatment for the degradation of the pesticides metaldehyde, clopyralid and mecoprop-Kinetics and reaction product formation. Water Res. 2016, 91, 285-294. [CrossRef] [PubMed]

22. Li, A.; Zhao, X.; Liu, H.; Qu, J. Characteristic transformation of humic acid during photoelectrocatalysis process and its subsequent disinfection byproduct formation potential. Water Res. 2011, 45, 6131-6140. [CrossRef] [PubMed]

23. Amarsanaa, B.; Park, J.Y. Effect of water back-flushing and PP beads in hybrid water treatment of multi-channel alumina MF and photocatalyst-coated PP beads. Desalinat. Water Treat. 2015, 54, 1457-1469. [CrossRef]

24. Gang, G.L.; Park, J.Y. Hybrid water treatment process of tubular carbon fiber ultrafiltration and photocatalyst-coated PP beads: Treatment mechanisms and effects of water back-flushing time. Desalinat. Water Treat. 2016, 57, 7721-7732. [CrossRef]

25. Park, Y.; Park, J.Y. Roles of adsorption and photo-oxidation in hybrid water treatment process of tubular carbon fiber ultrafiltration and PP beads with UV irradiation and water back-flushing. Desalinat. Water Treat. 2017, 61, 20-28. [CrossRef] 
26. Song, S.; Park, Y.; Park, J.Y. Roles of polypropylene beads and $\mathrm{pH}$ in hybrid water treatment of carbon fiber membrane and PP beads with water back-flushing. Membr. Water Treat. 2019, 10, 155-163. [CrossRef]

27. Lee, H.C.; Park, J.Y. Advanced water treatment of high turbidity source by hybrid process of ceramic microfiltration and activated carbon adsorption: Effect of water-back-flushing time and period. Membr. J. 2009, 19, 7-18. 